\title{
Simple Method for Determination of Perfusion and Ventila- tion-Perfusion Ratio of the Underventilated Elements (the Slow Compartment) of the Lung*
}

\author{
Robert A. Klocke † and Leon E. Farhi \\ (From the Department of Physiology, the State University of Nca' York at Buffalo, \\ Buffalo, N.Y.)
}

The degree of unevenness in distribution of inspired gas is of interest because it affects gas turnover in the alveoli and hence alveolar gas composition $(1,2)$. Since the various body organs are not in direct contact with the alveolar gas, this unevenness affects them only indirectly. From the standpoint of the peripheral tissues, the most important factor by which lung performance may be judged is the gas content of arterial blood. Poorly ventilated alveoli are rather innocuous if they are also poorly perfused. On the other hand, if considerable blood flow is present, these alveoli can be a source of serious embarrassment to the body since they have a marked influence upon arterial gas content.

Several methods for measuring distribution of pulmonary blood flow have been devised. Some are based on injection or inhalation of radioactive materials (3-6), but are too complicated or too costly for general use. Finley (7) has reported a method of estimating perfusion of poorly ventilated alveoli that requires simultaneous recording of alveolar $\mathrm{CO}_{2}$ and $\mathrm{N}_{2}$ (from which alveolar $\mathrm{O}_{2}$ is calculated) and arterial $\mathrm{O}_{2}$ tension. Briscoe and others (8) have described a method of evaluating pulmonary ventilation and perfusion that gives more detailed information but requires measurement of seven different parameters.

The desirability of a less complicated method of measuring the perfusion of the poorly ventilated alveoli and of estimating their ventilationperfusion ratio led to the present study. Inert gas washout is followed in the expired gas and in

* Submitted for publication February 28, 1963; accepted July 22, 1964.

Supported by the Wright Air Development Center, Wright-Patterson Air Force Base, Ohio, under contract AF 33(616)6823.

$\dagger$ Present address: Walter Reed Army Medical Center, Washington 12 , D. C. the arterial blood with a single instrument, the gas chromatograph. In conventional washout studies, expired $\mathrm{N}_{2}$ is monitored after the inspired gas is changed from air to $100 \% \mathrm{O}_{2}$. In normal subjects, however, the washout is rapid, and the amount of $\mathrm{N}_{2}$ eliminated in the late phase is low. In this situation it is practically impossible to avoid significant contamination with $\mathrm{N}_{2}$ for a variety of reasons, e.g., $\mathrm{N}_{2}$ dissolved in heparin, leakage of air into the sample, addition of $\mathrm{N}_{2}$ from Van Slyke grease, and so forth. Therefore, we decided to prebreathe subjects with helium and subsequently follow $\mathrm{He}$ rather than $\mathrm{N}_{2}$ washout.

\section{Theory}

\section{Methods}

Ventilation of the slow compartment. Although the lungs are probably composed of a vast number of alveoli with each alveolus having its own specific ventilation rate, the respiratory system has been treated effectively by several authors as if composed of two groups of alveoli, one well ventilated, the "fast compartment," and the other poorly ventilated, the "slow compartment" (9). The significance of the term "slow compartment" is discussed below. In the washout of inert gas, well-ventilated alveoli are rapidly cleared. In the late phase of the washout, only the slow compartment contributes inert gas to alveolar gas, and thus

$$
\dot{\mathrm{V}}_{\mathrm{A}} \times \mathrm{F}_{\mathrm{AHe}}=\dot{\mathrm{VS}} \times \mathrm{Fs}_{\mathrm{He}},
$$

where $\dot{V}$ represents ventilation and $F$ the fractional concentration of the inert gas. . A and $\mathrm{S}$ refer to the mixed alveolar gas and the slow compartment, respectively. For the sake of simplicity, in all further equations the subscript of the inert gas in question (in this case, helium) is omitted when speaking of fractional concentration. The same will subsequently also apply to content.

Rearranging Equation 1 and referring the fractional concentrations to $\mathrm{FA}_{\mathbf{A}_{0}}$, the alveolar fraction at time 0 ,

$$
\frac{\dot{\mathrm{VS}}}{\dot{\mathrm{VA}}}=\frac{\mathrm{FA}_{\mathrm{A}}}{\mathrm{FA}_{0}} \times \frac{\mathrm{FA}_{\mathrm{A}_{0}}}{\mathrm{Fs}_{\mathrm{S}}} .
$$

The ratio on the left side of Equation 2 describes the ventilation of the slow compartment as a fraction of the over-all 


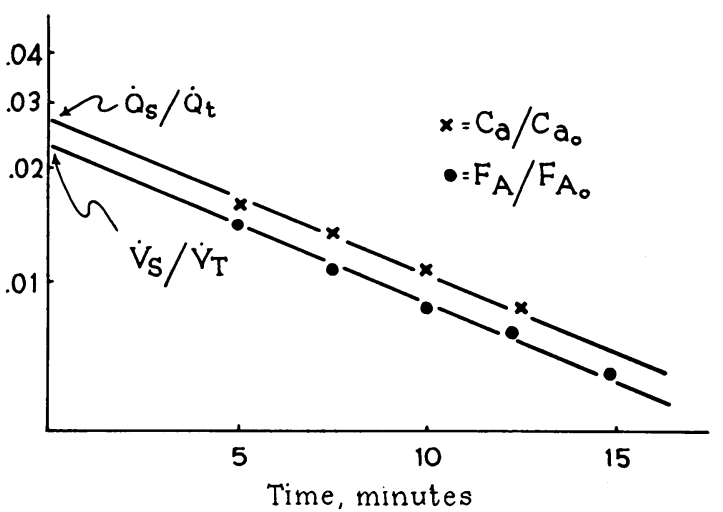

Fig. 1. Alveolar and arterial Rate of DECREASE of INERT GAS. The inert gas is plotted in both cases as a fraction of the control value. The vertical intercept of the extrapolated alveolar gas washout line indicates the fraction of alveolar ventilation originating in the slow compartment $(\dot{V} s / \dot{V} t)$, whereas the intercept of the blood washout curve defines the relative perfusion of this compartment $(\dot{Q} s / \dot{Q} t)$. Vertical distance between the two lines compares the $\dot{V} / \dot{Q}$ of this compartment to that of the whole lung. $\quad \mathrm{Ca}_{0}=$ content of arterial blood at time 0 ; $F_{A_{0}}=$ alveolar fraction at time 0 .

alveolar ventilation. The ratios on the right are ratios of fractional concentration. Since, in the system we use, the response of the gas chromatograph has been shown to be proportional to the fractional concentration of a gas (10), each ratio can be replaced by a ratio of chromatograph readings, obviating the need of calibrating the instrument. Equation 2, however, cannot be solved as it stands since Fs is unknown. This difficulty can be circumvented by using a graphic approach. The determined $\mathrm{FA}_{\mathrm{A}} / \mathrm{FA}_{0}$ values are plotted on a logarithmic scale as a function of the time at which the samples were obtained (Figure 1). In all subjects the curve that joins all these points eventually becomes a straight line. Such a straight line would also obtain if a uniform compartment were washed out and hence describes the virtual "slow compartment." Extrapolation of this straight line to time 0 determines an intercept value for $\mathrm{FA}_{\mathrm{A}} / \mathrm{F}_{\mathrm{A}_{0}}$. If it is assumed that at time 0 , that is, in the steady state preceding washout, the fraction of inert gas in the slow compartment was the same as that in the rest of the lung (i.e., $\mathrm{FA}_{\mathrm{A}_{0}} / \mathrm{Fs}=1$ ), then the intercept represents $\dot{\mathrm{V}} \mathrm{s} / \dot{\mathrm{V}}_{\mathrm{A}}$, or the fraction of the over-all alveolar ventilation contributed by the slow compartment.

Two assumptions are involved in this derivation. The first is that the fast compartment contributes no inert gas to the expirate; actually, since inert gas is being washed out of peripheral tissues, some of this gas must be eliminated by the fast compartment. After 5 minutes of washout, however, the inert gas content of mixed venous blood drops to $20 \%$ of its initial value (11). When the inert gas considered has a low solubility, it will not introduce a significant error even if it is eliminated in toto by the fast compartment. For example, if the gas has a Bunsen coefficient of 0.01 (approximately that of $\mathrm{N}_{2}$ or $\mathrm{He}$ ), and if the blood was initially equilibrated with 0.8 atmosphere of the gas, the mixed venous blood at 5 minutes will contain 0.16 vol per $100 \mathrm{ml}$ of the gas. Even if the ventilation-perfusion ratio of the fast compartment is equal to unity (an underestimation in most cases), the ratio between the inert gas fractional concentration in the alveolar gas at 5 minutes and at time 0 will be $0.0016 / 0.8$, or 0.002 , an amount too small to influence our results. In addition, since the subject breathed a helium mixture for only 1 hour before sampling in our experiments, peripheral tissues would not be fully saturated and blood returning from the tissues, i.e., mixed venous blood, would contain even less helium than the estimated $20 \%$ of the initial value.

The second assumption is that during the steady state the fraction of inert gas is the same throughout the lungs. This is correct only if all the elements in that lung have the same alveolar ventilation-perfusion ratio $\left(\dot{\mathrm{V}}_{\mathbf{A}} / \dot{\mathrm{Q}}\right)$ (12). When the mixed venous blood composition is normal or near normal and the fraction of the inert gas is 0.80 , the true fraction in any single alveolus may vary from 0.88 if the $\dot{V}_{A} / \dot{Q}$ is zero to 0.78 when $\dot{V}_{A} / \dot{Q}$ is 2 (12). This indicates that the value of $\dot{V} s / \dot{V}_{A}$ as read directly in Figure 1 may be in error by as much as $10 \%$ of its value. Thus an intercept value of 0.05 indicates in fact that the fraction of the ventilation to the slow compartment is between 4.5 and $5.5 \%$ of the total. This is not a large error and may be corrected after the perfusion to the slow compartment has been calculated.

Perfusion of the slow compartment. If it is assumed that after 5 minutes of washout helium content of the arterial blood is contributed solely by blood returning from the slow compartment,

$$
\dot{\mathrm{Q}} \mathrm{t} \times \mathrm{Ca}=\dot{\mathrm{Q}} \mathrm{s} \times \mathrm{Cs} \text {, }
$$

where $\dot{Q} t$ is the total blood flow, $\dot{Q}$ s the blood flow to the slow compartment, $\mathrm{Ca}$ the content of the arterial blood, and Cs the content in the blood perfusing the slow compartment.

In Figure 1 , where $\mathrm{Ca} / \mathrm{Ca}_{0}$ is plotted versus time on a semilogarithmic scale, all points obtained after 5 minutes fall on a straight line. Reasoning similar to that detailed under Ventilation of the slow compartment indicates that the intercept of this line with the ordinate axis determines the fractional perfusion of the slow compartment.

Equation 3 implies that no detectable amount of helium is added to the arterial blood either by the perfusion of the fast compartment or by direct shunts. The first part of this statement is certainly justified in view of the low solubility of helium. However, if mixed venous blood helium content at 5 minutes is still $20 \%$ of the initial value, the venous admixture of $1 \%$ of the total blood flow will change $\mathrm{Ca} / \mathrm{Ca}_{0}$ by 0.002 , a value that would be relatively insignificant. As mentioned above, however, peripheral tissues were not completely saturated with helium in our experiments, and thus the error involved would be less than estimated. Nevertheless, the combination of a high helium content in mixed venous blood and a high degree of venous admixture might render this assumption dangerous.

Ventilation-perfusion ratio of the slow compartment. Although from the data obtained the absolute value of the 
ventilation-perfusion ratio of the slow compartment cannot be calculated, this value can be compared to the ventilation-perfusion ratio of the whole lung by combining Equations 1 and 3 and rearranging as

$$
\left(\frac{\dot{\mathrm{V}} \mathrm{s}}{\dot{\mathrm{Q}}_{\mathrm{s}}}\right) /\left(\frac{\dot{\mathrm{V}}_{\mathrm{A}}}{\dot{\mathrm{Q}}_{\mathrm{t}}}\right)=\frac{\mathrm{FA}_{\mathrm{A}}}{\mathrm{Ca}} \times \frac{\mathrm{Cs}}{\mathrm{Fs}} .
$$

In this equation, neither Cs nor Fs is known, but they are related through $\alpha$, the solubility coefficient of helium in blood.

$$
\frac{\mathrm{Cs}}{\mathrm{Fs}}=\frac{\alpha(\mathrm{PB}-47)}{760},
$$

where $\mathrm{PB}=$ barometric pressure.

If it is assumed that the same equilibrium existed under control conditions,

$$
\frac{\mathrm{Ca}_{0}}{\mathrm{FA}_{0}}=\frac{\alpha(\mathrm{PB}-47)}{760},
$$

and the last fraction of Equation 4 may be replaced by $\mathrm{Ca}_{0} / \mathrm{FA}_{\mathrm{A}_{0}}$, after which the equation may be rearranged to read

$$
\left(\frac{\dot{V} \mathrm{~s}}{\dot{\mathrm{Q}} \mathrm{s}}\right) /\left(\frac{\dot{\mathrm{V}}_{\mathrm{A}}}{\dot{\mathrm{Q}_{\mathrm{t}}}}\right)=\frac{\mathrm{FA}_{\mathrm{A}}}{\mathrm{F}_{\mathrm{A}_{0}}} \times \frac{\mathrm{Ca}_{0}}{\mathrm{Ca}} \text {. }
$$

$\mathrm{FA}_{\mathrm{A}} / \mathrm{FA}_{\mathrm{A}_{0}}$ simply represents a ratio of chromatograph readings for alveolar gas, and $\mathrm{Ca}_{0} / \mathrm{Ca}$ the ratio of readings for blood samples.

Here again the assumption that the fraction of helium is the same throughout the lung is implicit, since Equation 6 assumes equilibrium of partial pressures between alveolar gas and arterial blood. This condition is present only when the $\dot{V}_{A} / \dot{Q}$ of all the elements is the same. The maximal error introduced by this assumption is below $10 \%$ of the calculated value.

It is also possible to obtain the relative ventilation-perfusion ratio of the slow compartment (i.e., the value of that ratio for this compartment in respect to that of the whole lung, as expressed in Equation 7) by dividing $\mathrm{FA}_{\mathrm{A}} / \mathrm{F}_{\mathrm{A}_{0}}$ by $\mathrm{Ca} / \mathrm{Ca}_{0}$ measured at the same time during the washout.

\section{Procedure}

The supine subject breathed an $80 \% \mathrm{He}-20 \% \mathrm{O}_{2}$ mixture supplied to an airtight face mask from a gas cylinder fitted with a demand valve. The normal subjects were seasoned laboratory workers who had been subjected to similar measurements several times before this experiment. After 60 minutes the face mask was removed, and the subject breathed room air through a mouthpiece equipped with one-way check valves that allowed sampling of end-expiratory gas. The face mask was used during the helium breathing period instead of a mouthpiece to prevent leakage and discomfort to the subject. The mask, however, would not allow representative sampling of alveolar gas due to the large dead space, so the mouthpiece was substituted before sampling. The subject breathed through a low resistance valve, and gas samples were obtained in $30-\mathrm{ml}$ syringes from the expiratory side of the valve. The whole sampling procedure took place in a few seconds.
TABLE I

Relative perfusion and ventilation of the slow compartment

\begin{tabular}{lccc}
\hline \multicolumn{1}{c}{ Subject } & $\dot{\mathrm{V}} \mathrm{s} / \dot{\mathrm{V}} \mathrm{t}$ & $\dot{\mathrm{Q}} \mathrm{s} / \dot{\mathrm{Q}} \mathrm{t}$ & $\begin{array}{c}(\dot{\mathrm{V}} \mathrm{s} / \dot{\mathrm{Q}} \mathrm{s}) / \\
(\dot{\mathrm{V}} / \mathbf{\mathrm { Q }} \mathrm{t})\end{array}$ \\
\hline Normal & $\%$ & $\%$ & \\
M.L. & & & \\
D.M. & 2.2 & 2.7 & 0.82 \\
D.B. & 1.7 & 2.2 & 0.77 \\
L.F. & 1.4 & 1.5 & 0.93 \\
R.K. & 2.0 & 3.3 & 0.61 \\
Mean & 1.7 & 1.9 & 0.89 \\
Pulmonary emphysema & 1.8 & 2.3 & 0.80 \\
W.G. & 10.4 & 32.5 & 0.32 \\
\hline
\end{tabular}

* $\dot{V} s=$ ventilation of the slow compartment; $\dot{V} t=$ total alveolar ventilation; $\dot{Q} \mathrm{~s}=$ perfusion of the slow compartment; $\dot{\mathrm{Q}} \mathrm{t}=$ total alveolar perfusion; $\dot{\mathrm{V}}_{\mathrm{A}}=$ alveolar ventilation.

Arterial blood was sampled through a no. 18 Riley needle in place in the left brachial artery. Clotting was prevented by filling the dead space of the $30-\mathrm{ml}$ sampling syringe with sterile heparin.

Both blood and gas samples were taken just before cessation of helium breathing and $5,7.5,10,12.5$, and 15 minutes thereafter. Samples were analyzed on a Beckman GC-2 gas chromatograph, with the method developed by Edwards, Velasquez, and Farhi (10). Chromatograph output was recorded on a $1 \mathrm{mv}$ Minneapolis-Honeywell recorder. Helium content of $1 \mathrm{ml}$ of gas and $3 \mathrm{ml}$ of blood was determined. Single gas samples were analyzed. Blood samples were analyzed in duplicate and averaged.

\section{Results and Discussion}

The helium curves of alveolar gas and arterial blood in a typical experiment are shown in Figure 1. Both curves are extrapolated back to the initial time of the washout in order to compute the contribution of ventilation and perfusion of the slow compartment to the total ventilation and perfusion.

The results for five normal subjects appear in Table I. The mean pulmonary blood flow perfusing the slow compartment was $2.3 \%$ of the total blood flow, whereas the mean ventilation of this compartment was $1.8 \%$ of the total ventilation. The mean $(\dot{\mathrm{V}} \mathrm{s} / \dot{\mathrm{Q}} \mathrm{s}) /\left(\dot{\mathrm{V}}_{\mathrm{A}} / \dot{\mathrm{Q}} \mathrm{t}\right)$ ratio is 0.80 , indicating that the ventilation-perfusion ratio of the slow compartment is slightly smaller than the over-all ventilation-perfusion ratio. This is in agreement with data reported previously (4). The gas and blood washout curves 


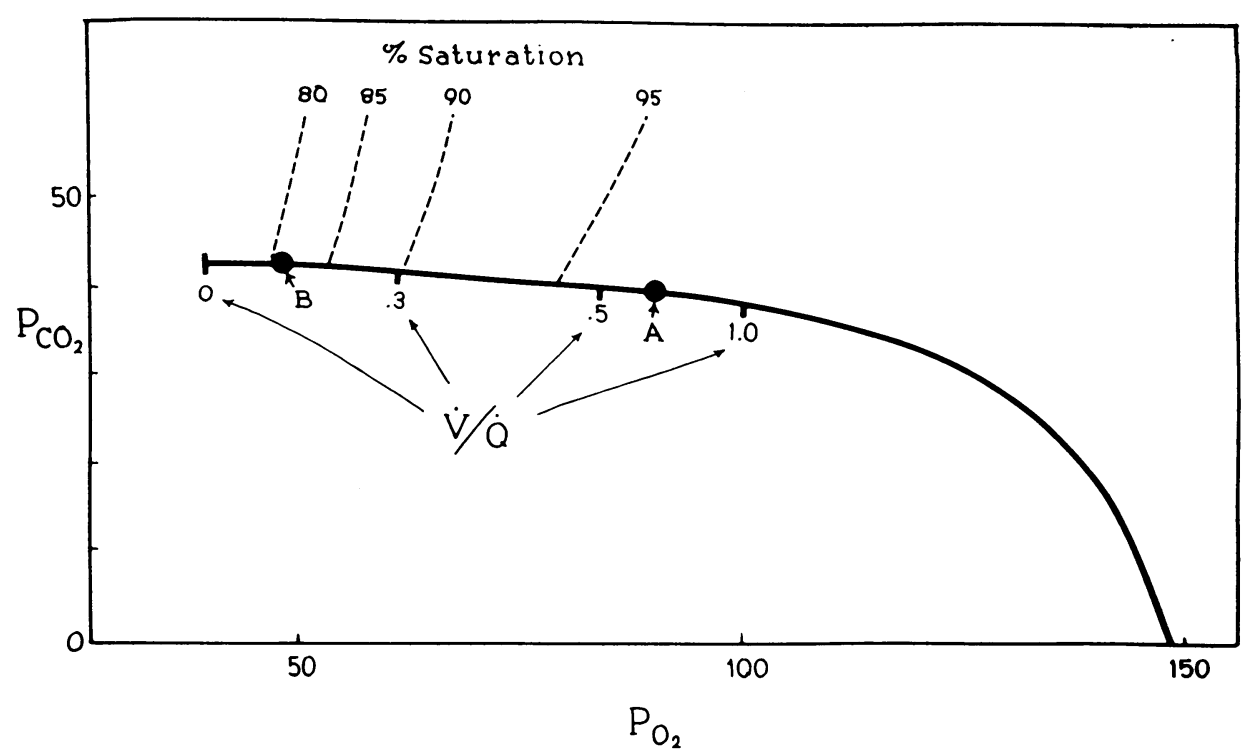

Fig. 2. Alveolar ventilation-perflion ( $\dot{V}_{\text {A }} / \dot{Q}$ ) LINE SHOWING THE POSITION OF THE SLOW Compartment. Point $\mathrm{A}$ is the mean for the normal subjects; point $\mathrm{B}$ is from an emphysema patient. The $\mathrm{O}_{2}$ saturation of the blood returning from the slow compartment can be read on the saturation isopleth.

are parallel in all subjects, indicating that the slow compartment, identified solely on the basis of its ventilation, is uniformly perfused.

The continuous repetition of the term "slow compartment" may require clarification at this point. Although in a limited number of cases it is possible to imagine the lung as composed of two or more homogeneous compartments, differing in some respects from each other, there is no evidence whatsoever that these compartments, as such, exist in normal man, or for that matter, in most patients. It is much more logical to imagine a continuous spectrum, with a gradation of properties. This system, however, is next to impossible to describe simply, hence the accepted "compartments" presentation, which has also been utilized in this study. This description pertains to a model lung that could give the same results as the lung being studied. Thus, when the $\dot{V} s / \dot{Q} s$ is said to be half the $\dot{V}_{A} / \dot{Q} t$ value, it should be interpreted only as saying that the lungs of the subject in question behave as if they included a homogeneous compartment in which the ventilation-perfusion ratio is half that of the total system. This is basically also what is stated in describing blood clearance values, where it is assumed that blood flow from an organ can be divided into two compartments, one of which has the properties of the incoming blood whereas the other has been completely "cleared" of a given component.

In these experiments, end-tidal gas composition was considered equal to alveolar composition. Although this is not absolutely true, evidence has been presented that end tidal gas is more representative of alveolar gas than a sample delivered with a forced expiration (13). In addition, the effect of a forced expiration on the distribution of the alveolar ventilation cannot be accurately assessed and may produce significant changes in the distribution of the ventilation.

We have assumed that there is no significant barrier to the diffusion of helium between the alveolus and the capillary blood. Certainly in normals this is true. Although the diffusing capacity is often altered in patients with distribution disturbances, it is unlikely that a significant alveolar-capillary difference exists in these patients. Recent evidence suggests that there is no barrier to gaseous diffusion even in patients with "alveolar-capillary block syndrome" (14).

In addition to the five normal subjects, Table I presents the data obtained from the study of one patient with chronic obstructive emphysema. 
This diagnosis was based on the presence of clinical signs and symptoms of the disease (wheezing, dyspnea on moderate exercise, cough, barrel chest with limited motion, râles, and wheezes) and on a maximal breathing capacity below half the predicted value. The ventilation of the slow compartment was about $10 \%$ of the total, but the perfusion was roughly one-third of the total. Thus the measurement of distribution of ventilation alone would underestimate the severity of the problem. The low ventilationperfusion ratio of this compartment as compared to the over-all $\dot{\mathrm{V}}_{\mathbf{A}} / \dot{\mathrm{Q}} \mathrm{t}$ agrees well with data obtained in similar patients using more sophisticated methods (6-8).

In Figure 2 a ventilation-perfusion distribution curve is constructed on a $\mathrm{PO}_{2}-\mathrm{PCO}_{2}$ diagram using a mixed venous point with a $\mathrm{PCO}_{2}$ of $46 \mathrm{~mm}$ and a $\mathrm{Po}_{2}$ of $40 \mathrm{~mm}$ (15). The ventilation-perfusion ratio of the slow compartment can be calculated from $(\dot{\mathrm{V}} \mathrm{s} / \dot{\mathrm{Q}} \mathrm{s}) /\left(\dot{\mathrm{V}}_{\mathbf{A}} / \dot{\mathrm{Q}} \mathrm{t}\right)$, if an over-all ventilation-perfusion ratio of 0.8 is assumed. The mean $\dot{V} \mathbf{s} / \dot{Q} s$ of the normal subjects is plotted on the curve, and the arterial point of the slow compartment lies at a $\mathrm{PCO}_{2}$ of $42 \mathrm{~mm}$ and a $\mathrm{Po}_{2}$ of $92 \mathrm{~mm}$. On the same $\dot{\mathrm{V}}_{\mathbf{A}} / \dot{\mathrm{Q}}$ line, an additional point represents the gas tensions of the blood returning from the slow compartment of the lungs of patient W.G. from Table I. The $\mathrm{O}_{2}$ saturation of blood leaving the slow compartment in this patient is well below that of the blood leaving the slow compartment in the normals. Strictly speaking, it is not possible to use the same $\dot{V}_{A} / \dot{Q}$ line for both normals and the patient, because the arterial blood $\mathrm{O}_{2}$ content of the latter must be lower. Therefore, if the arteriovenous $\mathrm{O}_{2}$ difference were the same as in normals, the mixed venous point should be displaced to the left by a few mm $\mathrm{Po}_{2}$. When the $\dot{\mathrm{V}}_{\mathbf{A}} / \dot{\mathrm{Q}}$ line based on this new mixed venous point is drawn, however, it lies very near the normal line. For this reason, and since Figure 2 is designed only to give an indication of approximate blood gas composition, the same $\dot{V}_{\mathbf{A}} / \dot{Q}$ line has been used for both normals and the patient.

Thus, although the ventilation-perfusion ratio of the slow compartment expressed as a fraction of the over-all ventilation-perfusion ratio yields no absolute parameters of pulmonary function, it is a useful and easily obtainable index of the relative overperfusion of the slow compartment.

\section{Summary}

The rate of disappearance of inert gas during washout was followed simultaneously in the alveolar gas and in the arterial blood. This allows calculation of the relative perfusion of the hypoventilated (slow) compartment and comparison of its ventilation-perfusion ratio to the alveolar ventilation-perfusion ratio $\left(\dot{\mathrm{V}}_{\mathbf{A}} / \dot{\mathrm{Q}}\right)$ of the total respiratory system. In five normal subjects, the slow compartment received $1.8 \%$ of the total ventilation and $2.3 \%$ of the lung perfusion and had a $\dot{V}_{A} / \dot{Q}$ ratio of $81 \%$ of the total ratio. By comparison, study of an emphysematous subject showed that $10 \%$ of the alveolar ventilation was distributed to the slow compartmènt, whereas $33 \%$ of the total blood flow perfused this compartment. The procedure requires only one analytical method and therefore is applicable on a large scale.

\section{References}

1. Bouhuys, A., and G. Lundin. Distribution of inspired gas in lungs. Physiol. Rev. 1959, 39, 731.

2. Briscoe, W. A., and A. Cournand. The degree of variation of blood perfusion and ventilation within the emphysematous lung, and some related considerations in Ciba Foundation Symposium on Pulmonary Structure and Function. Boston, Little, Brown, 1962, p. 304.

3. Gurtner, H. P., W. A. Briscoe, and A. Cournand. Studies of the ventilation-perfusion relationships in the lungs of subjects with chronic pulmonary emphysema, following a single intravenous injection of radioactive krypton $\left(\mathrm{Kr}^{85}\right)$. I. Presentation and validation of a theoretical model. J. clin. Invest. 1960, 39, 1080.

4. West, J. B., and C. T. Dollery. Distribution of blood flow and ventilation-perfusion ratio in the lung, measured with radioactive $\mathrm{CO}_{2}$. J. appl. Physiol. 1960, 15, 405.

5. Ball, W. C., Jr., P. B. Stewart, L. G. S. Newsham, and D. V. Bates. Regional pulmonary function studied with xenon ${ }^{133}$. J. clin. Invest. 1962, 41, 519.

6. Bentivoglio, L. G., F. Beerel, A. C. Bryan, P. B. Stewart, B. Rose, and D. V. Bates. Regional pulmonary function studied with xenon $^{133}$ in patients with bronchial asthma. J. clin. Invest. 1963, 8, 119.

7. Finley, T. N. The determination of uneven pulmonary blood flow from the arterial oxygen tension 
during nitrogen washout. J. clin. Invest. 1961, 40, 1727.

8. Briscoe, W. A., E. M. Cree, J. Filler, H. E. J. Houssay, and A. Cournand. Lung volume, alveolar ventilation and perfusion interrelationships in chronic pulmonary emphysema. J. appl. Physiol. 1960, 15, 785.

9. Briscoe, W. A., and A. Cournand. Uneven ventilation of normal and diseased lungs studied by an open-circuit method. J. appl. Physiol. 1959, 14, 284.

10. Edwards, A. W. T., T. Velasquez, and L. E. Farhi. Determination of alveolar capillary temperature. J. appl. Physiol. 1963, 18, 107.

11. Ledbetter, M. K. Personal communication.
12. Rahn, H., and L. E. Farhi. Ventilation-perfusion relationship in Ciba Foundation Symposium on Pulmonary Structure and Function. Boston, Little, Brown, 1962, p. 139.

13. Rahn, H. A concept of mean alveolar air and the ventilation-bloodflow relationship during pulmonary gas exchange. Amer. J. Physiol. 1949, 158, 21.

14. Finley, T. N., E. W. Swenson, and J. H. Comroe, Jr. The cause of arterial hypoxemia at rest in patients with "alveolar-capillary block syndrome." J. clin. Invest. 1962, 41, 618.

15. Rahn, H., and W. O. Fenn. A Graphical Analysis of the Respiratory Gas Exchange. Washington, D. C., American Physiological Society, 1955.

\section{SPECIAL NOTICE TO SUBSCRIBERS}

Post Offices will no longer forward the Journal when you move.

Please notify The Journal of Clinical Investigation, Business Office, 10 Stoughton Street, Boston, Mass. 02118, at once when you have a change of address, and do not omit the $\mathrm{Zip}$ Code number. 